\title{
Experimental Investigation and Comparison of Shell Tube and Plate Heat Exchanger used in Water Chillers
}

\author{
D.O.I - 10.51201/Jusst12548 \\ http://doi.org/10.51201/Jusst12548 \\ S.C. Shamkuwar ${ }^{1 *}$, Nitin Chopra ${ }^{2}$, Mihir Kulkarni ${ }^{4}$ and Nikhil Ahire ${ }^{4}$ \\ ${ }^{I}$ Assistant Professor, Department of Mechanical Engineering, VIIT Pune, Pune, India \\ 2 Mechanical Design Engineer, ION Energy, Mumbai, India \\ 3,4 Student, Department of Mechanical Engineering, VIIT Pune, Pune, India
}

\begin{abstract}
The main objective of the paper is to compare the performance of Shell and tube heat exchanger (STHE) and Plate heat exchanger (PHE) used in chillers. The paper deals with experimental investigation and comparison, which is based on actual testing of STHE and PHE. Both heat exchangers were designed and tested for a heat load of $6000 \mathrm{kcal} / \mathrm{hr}$. In both types of heat exchangers, the primary working fluid used is Refrigerant $R 22$ and secondary working fluid used is water. Theoretical analysis shows that PHE has a $9.67 \%$ less heat transfer area than STHE. Experimental results show that overall heat transfer coefficient (OHTC) for PHE is higher than STHE by $30.96 \%$. The paper also includes a comparison of the heat transfer rate $(Q)$ of the two heat exchangers experimentally.
\end{abstract}

Keywords: Shell and tube heat exchanger, plate heat exchanger, R22

\section{Introduction}

STHE and PHE are used in water chiller applications as evaporator and condenser. STHE, as shown in Figure 1, consists of an annular cylindrical shell made up of mild steel and a helical coil micro finned copper tube, which is placed in the annular portion of the shell. In the current study, STHE fins present on the circumference of the helical tube acts as a baffle. Refrigerant R22 is passed through tubes, and domestic water is passed through the annular cylindrical shell. Water is passed into the annular cylinder from side opening, and exit is given from the top. At the bottom of the annular cylinder, a drain hole is made to carry out the maintenance PHE consists of alternate channels for primary and secondary fluids, separated by a corrugated metal plate as shown in Figure 2. The plate is made of stainless steel because of its ability to withstand high temperatures, its strength, and its corrosion resistance $[1,2]$.
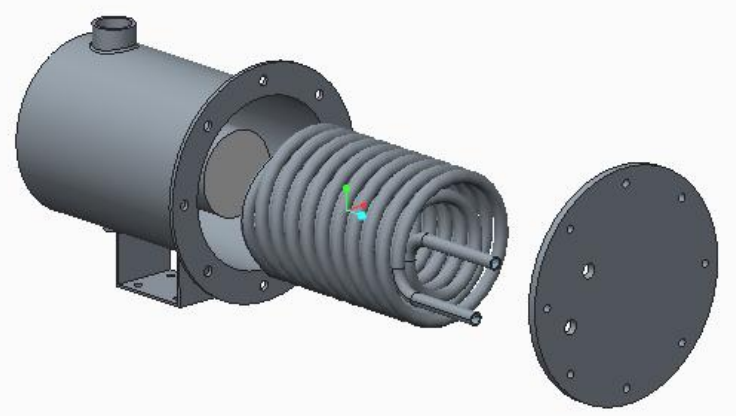

Figure 1. CAD Model of STHE

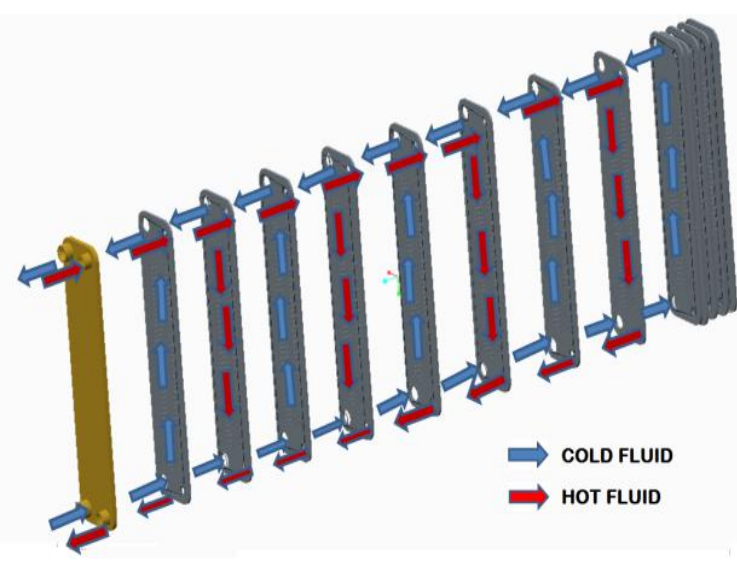

Figure 2. Exploded View of PHE 
A chiller is a thermal device which takes heat from a liquid via a vapour-compression or absorption refrigeration system. Chillers are used in applications where maintaining the temperature of a system and preventing the system from overheating is needed. It is also used in industrial applications such as injection and blow moulding, metalworking cutting oils, food and beverage processing, etc. with controlled cooling rate [3]]. Several researchers have done thermal design of STHE exchanger with optimization of mass flow rate and baffle spacing. The study concludes that pressure drop increases with an increase in fluid flow rate, which increases pumping power. Tube pitch ratio, tube length, tube layout as well as baffle spacing ratio was found to be essential design parameters which have a direct effect on pressure drop and cause a conflict between the effectiveness $[4,5,6]$.

The literature shows that in PHE, the thermal resistance is inversely proportional to the heat transfer rate through the slab. After the critical value of through-plane thermal conductivity, the convective thermal resistance controls the total heat transfer rate between fluid streams [7, 8]. Leakage free application is a significant advantage of STHE. In contrast, the ability to expand or reduce the thermal capacity by adding or reducing plates is a significant advantage for the PHE [9, 10]. The objective of the current paper critically studies and design the STHE and PHE for chillers, theoretically and experimentally study their performance and suggest the best one.

\section{Heat Exchanger Used for Experimentation}

\subsection{Shell and tube exchanger}

Shell and tube heat exchangers are designed normally by using either Kern's method or BellDelaware method. Kern's method is mostly used for the preliminary design and provides conservative results whereas; the Bell-Delaware method is more accurate and can provide detailed results. It can predict and estimate the pressure drop and heat transfer coefficient with better accuracy. For the current analysis, is designed by D.Q. Kern's method for heat load of $6000 \mathrm{kcal} / \mathrm{hr}$. [10, 11]. The shell and tube heat exchanger is designed by using a considering counter-flow type Helical coil heat exchanger.

The steps of designing are described as follows:

1) As shown in Figure 3 From inputs like hot fluid inlet and outlet temperatures, cold fluid inlet temperature and mass flow rates of the two fluids are calculated. The energy balance equation may be given as,

$$
Q=m C_{p} \Delta T
$$

Where $C_{p}$ is the specific heat of the fluid.

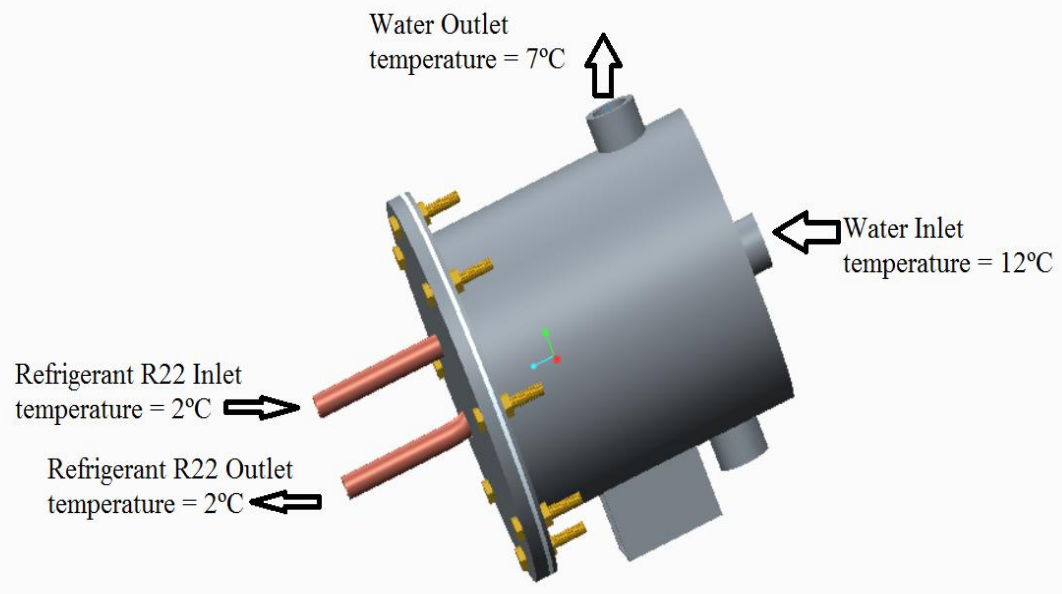

Figure 3. Inlet and Outlet Temperature of Water and R22 in STHE 
2) The logarithmic mean temperature difference (LMTD) was found out by equation,

$$
\mathrm{LMTD}=\frac{\Delta T_{1}-\Delta T_{2}}{\ln \left(\frac{\Delta T_{1}}{\Delta T_{2}}\right.}
$$

3) Table 1 shows all geometrical dimensions selected for the shell and tube exchanger. Next step is to calculate the heat transfer area $\left(\mathrm{A}_{0}\right)$ required for the heat exchanger based on an assumednumber of the tube, tube diameter, the diameter of shell and tube thickness with the help of following expressions:

$$
\mathrm{A}_{0}=\frac{\mathrm{Q}}{\mathrm{U} 0 * \Delta \mathrm{T}}
$$

Also,the length of the tube is calculated as,

$\mathrm{L}=\frac{\mathrm{Ao}}{\mathrm{NT} \pi \mathrm{do}}$

Table 1. Geometrical Dimensions of SHTE

\begin{tabular}{|c|c|c|c|}
\hline Sr No & Parameter & Value & Unit \\
\hline 1 & The outer diameter of the tube $\left(\mathrm{d}_{\mathrm{o}}\right)$ & 12.7 & $\mathrm{~mm}$ \\
\hline 2 & The inner diameter of the tube & 9.4 & $\mathrm{~mm}$ \\
\hline 3 & Number of tubes $(\mathrm{N})$ & 1 & - \\
\hline 4 & Number of passes & 2 & - \\
\hline 5 & Baffle spacing & 2.54 & $\mathrm{~mm}$ \\
\hline 6 & Triangular pitch & $25.4(1$ ”) & $\mathrm{mm}$ \\
\hline
\end{tabular}

\subsection{Plate Type Heat Exchanger}

According to required conditions plate heat exchanger was selected from 'Swep' company catalogue. The dimensions selected from the design catalogue are mentioned in Table 2.

Table 2.Geometrical Dimensions of PHE

\begin{tabular}{|l|l|c|c|}
\hline \multirow{2}{*}{} & \multicolumn{3}{|c|}{ Geometrical dimensions of PHE } \\
\cline { 2 - 4 } & \multicolumn{1}{|c|}{ Parameter } & Value & Unit \\
\hline 1 & Number of plates & 30 & - \\
\hline 2 & Length of plate & 306 & $\mathrm{~mm}$ \\
\hline 3 & Height of plate & 80.3 & $\mathrm{~mm}$ \\
\hline 4 & Width of plate & 106 & $\mathrm{~mm}$ \\
\hline
\end{tabular}

\section{Experimental Setup}

\subsection{Experimental Setup}

The experimental arrangement is shown in figure 4. It consists of three parts - VCRS (Vapor compression refrigeration system), cooling tower and the water tank.

- The VCRS system - It consists of four main components - Evaporator, compressor, condenser and expansion valve. All these components are connected through pipes. Liquid refrigerant flows into the evaporator and absorbs latent heat from the other working fluid (water in this case) and converts into vapour form. The heat exchangers to be tested are used as an evaporator (case1 STHE and case2 PHE). The compressor compresses this vapour refrigerant to high pressure and passes it to the condenser. This high pressurized refrigerant loses its heat to water from the cooling tower and gets converted into liquid form. Then the 
high pressurized liquid refrigerant flows to the capillary tube, where the pressure of refrigerant decreases. Refrigerant is then passed to the evaporator tube and the cycle is repeated.

- The cooling tower - It is used to absorb heat from the condenser using water. The heat absorbed by water is rejected to the atmosphere. The cooling tower is used to increase the Coefficient of performance of the system.

- The water tank- Water from the water tank at atmospheric conditions is sent to the evaporator of the VCRS system with the help of a screw-type flow control valve. The Flow control valve is used to control the mass flow rate of water to the shell of the evaporator. The heat from this water is transferred to refrigerant in the evaporator, thus the temperature of water decreases. The cooled water is passed to the water tank. An electric heating coil is introduced in the water tank to maintain the temperature of water flowing to the evaporator, thus avoiding large input temperature drop during testing.

\subsection{Instruments used for testing}

- Two separate pressure gauges are installed- one before the compressor and one after the compressor. The first measures the Suction pressure and the other measures the Discharge pressure.

- Laser Thermometer (or Laser temperature sensor) - It is used to measure the temperature of the working fluids at various points of the system. The laser is pointed at a required point and held for a second on a pipe of the system and the temperature of the fluid flowing through the pipe is measured and displayed on the digital display of the laser thermometer.

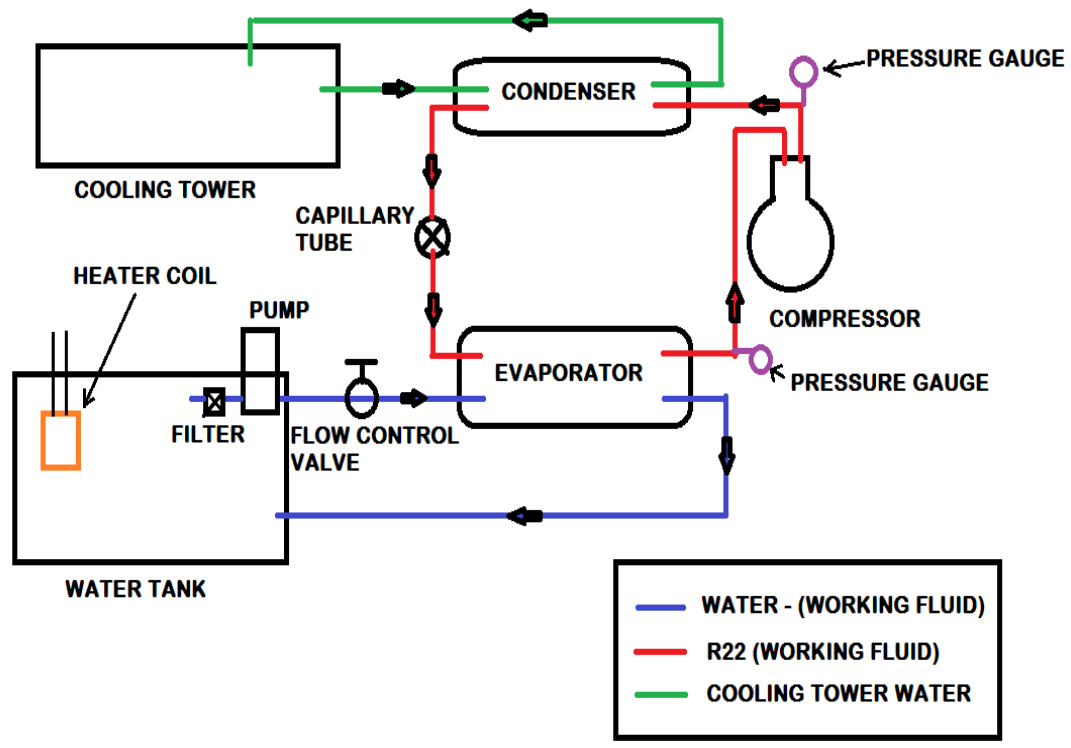

Figure4. Experimental Setup

\subsection{Experimental procedure}

All the components of the system were assembled as shown in Figure 3. All the pipes of the system were sealed by copper brazing. The system was then filled with nitrogen gas to check for leakages. Then refrigerant was filled into the system. The inlet water pump was turned on and the volume flow rate of water was measured and adjusted to $0.333 \mathrm{~kg} / \mathrm{s}$. The compressor motor was then turned on and thus the entire system started working. The system came into steady-state after $10-15$ minutes. Temperatures at inlet and outlet of the working fluids were then measured using the laser thermometer and suction and discharge pressures were noted down using the installed pressure gauges. Numbers of readings were taken at an interval of 10 minutes after every set of readings. 


\section{Results and Discussion}

Table 3 show the observations from the conducted test. The readings are taken at an interval of 10 minutes. Likewise, 4 readings are taken. The parameters that were measured for both heat exchangers were suction and discharge pressure refrigerant and water inlet-outlet temperature.

Table 3. Observation Table for STHE

\begin{tabular}{|c|c|c|c|c|c|c|c|c|}
\hline \multirow{2}{*}{ Quantity } & \multicolumn{4}{|c|}{ Readings for STHE } & \multicolumn{5}{c|}{ Readings for PHE } \\
\cline { 2 - 10 } & $\mathbf{1}$ & $\mathbf{2}$ & $\mathbf{3}$ & $\mathbf{4}$ & $\mathbf{1}$ & $\mathbf{2}$ & $\mathbf{3}$ & $\mathbf{4}$ \\
\hline Mass flow rate $(\mathrm{kg} / \mathrm{s})$ & 0.33 & 0.33 & 0.33 & 0.33 & 0.33 & 0.33 & $\begin{array}{c}0.3 \\
3\end{array}$ & 0.33 \\
\hline Suction pressure (bar) & 5 & 5 & 5 & 5 & 4 & 4 & 4 & 4 \\
\hline Discharge pressure (bar) & 13 & 13 & 13 & 13 & 20 & 20 & 20 & 20 \\
\hline Refrigerant inlet temperature $\left({ }^{\circ} \mathrm{C}\right)$ & -2 & -1 & 0.5 & 0.9 & -5 & -5.4 & -5.6 & -6 \\
\hline $\begin{array}{c}\text { Refrigerant outlet temperature } \\
\left({ }^{\circ} \mathrm{C}\right)\end{array}$ & 17 & 16.2 & 15.1 & 14.3 & 10.6 & 9.9 & 9.2 & 9 \\
\hline Water inlet temperature $\left({ }^{\circ} \mathrm{C}\right)$ & 19.4 & 18.3 & 17.1 & 16.2 & 12.7 & 12.1 & $\begin{array}{c}11 . \\
8\end{array}$ & 11.6 \\
\hline Water outlet temperature $\left({ }^{\circ} \mathrm{C}\right)$ & 15.4 & 14.5 & 13.6 & 12.7 & 8.1 & 7.7 & 7.5 & 7.5 \\
\hline
\end{tabular}

From the readings shown in Table 3 and using the following equation, the actual Q for STHE is calculated as Equation (1). Where $\mathrm{Cp}$ is the specific heat of water $(4.8170 \mathrm{KJ} / \mathrm{kg}$.), $\Delta \mathrm{T}$ is a difference in temperatures of water at the inlet and outlet of the heat exchanger.

To calculate the actual $\mathrm{U}_{\mathrm{O}}\left(\mathrm{U}_{\text {actual }}\right)$ of the STHE the following equation is used.

$Q=U_{\text {actual }} \times A \times(\Delta T)_{L M}$

$U_{\text {actual }}=\frac{Q}{A x(\Delta T)_{L M}}$

$(\Delta \mathrm{T}) \mathrm{LM}$ is the log mean temperature difference (LMTD). From the above calculations, the value of the actual heat transfer coefficient was calculated for each reading and the average heat transfer coefficient is $1043 \mathrm{~W} / \mathrm{m}^{2} \mathrm{k}$ [Table 4]. For the PHE, readings were taken in an exactly similar manner and calculations were done by using equation 5 and 6 . The observations noted during the testing and calculations of PHEs are as given in Table4. The $U_{\text {actual }}$ is calculated similarly by using (5). The estimations are shown in Table 4. From the above table, the average value of actual $\mathrm{U}_{\mathrm{O}}$ is calculated as $1366 \mathrm{~W} / \mathrm{m}^{2} \mathrm{k}$.

Table 4. Estimation of STHE and PHE.

\begin{tabular}{|c|c|c|c|c|c|c|c|c|}
\hline \multirow{2}{*}{ Quantity } & \multicolumn{4}{|c|}{ Readings for STHE } & \multicolumn{4}{c|}{ Readings for PHE } \\
\cline { 2 - 9 } & $\mathbf{1}$ & $\mathbf{2}$ & $\mathbf{3}$ & $\mathbf{4}$ & $\mathbf{1}$ & $\mathbf{2}$ & $\mathbf{3}$ & $\mathbf{4}$ \\
\hline $\begin{array}{c}\text { Temperature } \\
\text { difference } \Delta \mathrm{T}\left({ }^{\circ} \mathrm{C}\right)\end{array}$ & 4 & 3.8 & 3.7 & 3.5 & 4.6 & 4.4 & 4.3 & 4.2 \\
\hline Heat load Q $(\mathrm{kW})$ & 5582.6 & 5303.5 & 5163.9 & 4884.8 & 6420.1 & 6140.9 & 6001.4 & 5861.8 \\
\hline $\begin{array}{c}\text { LMTD }(\Delta \mathrm{T}) \mathrm{LM} \\
\left({ }^{\circ} \mathrm{C}\right)\end{array}$ & 7.57 & 6.76 & 5.91 & 5.42 & 6.0 & 6.1 & 6.4 & 6.6 \\
\hline Uactual $\left(\mathrm{W} / \mathrm{m}^{2} \mathrm{k}\right)$ & 930.8 & 998.3 & 1103.9 & 1137.7 & 1496.4 & 1407.8 & 1313.4 & 1246.5 \\
\hline
\end{tabular}

Figure 5 shows that the UO increases from $930.8 \mathrm{~W} / \mathrm{m}^{2} \mathrm{k}$ to $1137.7 \mathrm{~W} / \mathrm{m}^{2} \mathrm{k}$ as heat transfer rate decreases 5582.5 to $4884.9 \mathrm{~kW}$. Even though it increases, the heat transfer rate is decreased due to a decrease in LMTD from $7.57{ }^{\circ} \mathrm{C}$ to $5.42{ }^{\circ} \mathrm{C}$. Figure 6 shows that the UO decreases from $1496.4 \mathrm{~W} / \mathrm{m}^{2} \mathrm{k}$ to $1246.5 \mathrm{~W} / \mathrm{m}^{2} \mathrm{k}$. as heat transfer rate decreases from $6420.2 \mathrm{~kW}$ to $5861.8 \mathrm{~kW}$. As the temperature of water decreases from $12.7^{\circ} \mathrm{C}$ to $11.6^{\circ} \mathrm{C}$, the density of water increases and viscosity increases which 
results in a decrease in Reynolds number. As Reynolds number is directly proportional to UO, when Reynolds number decreases, UO also decreases.

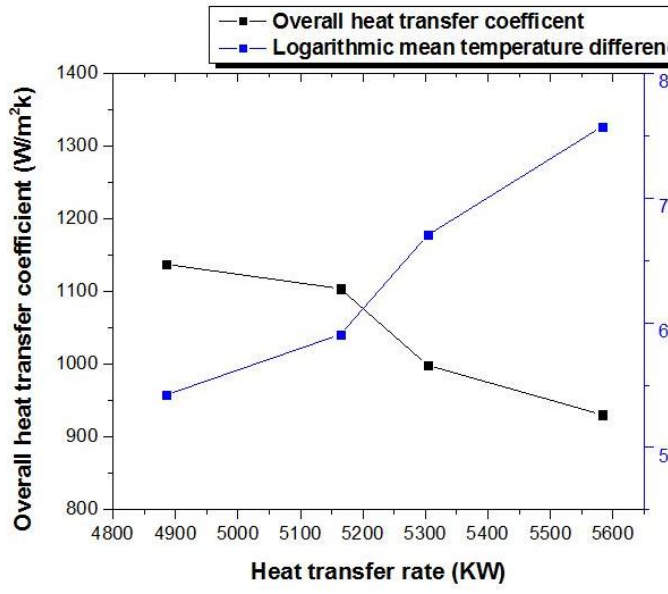

Figure5. Variation of $U_{0}$ and LMTD with $Q$ for STHE

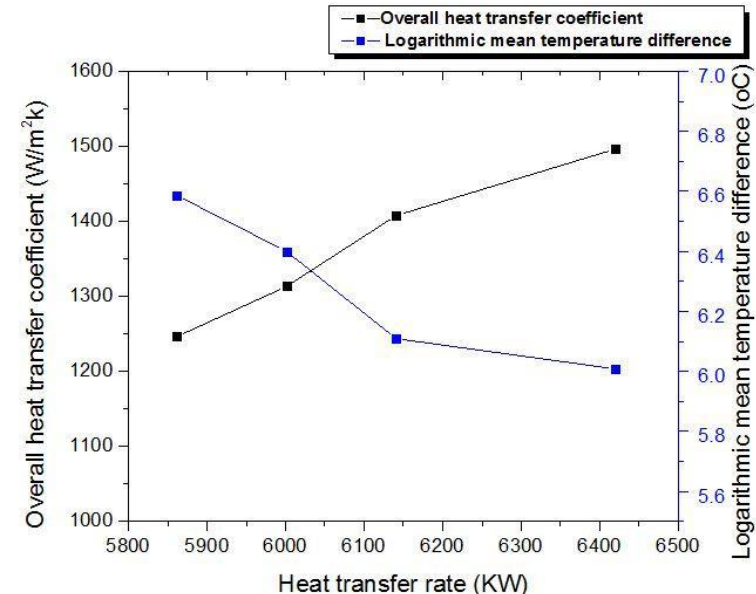

Figure 6. Variation of $U_{0}$ and LMTD with Q for PHE

Figure 7 shows that UO of PHE is higher than STHE by $30.96 \%$ due to decreased convective heat transfer coefficient, constant change in velocity and turbulence in PHE. The turbulence in STHEisdue to micro circular fins (10 fins per inch) provided on the outer surface of the tube. Hence turbulence in PHE is higher than STHE results decrease in convective resistance. Figure 8 shows that the heat transfer rate of PHE (average $\mathrm{Q}=5233.7 \mathrm{~kW}$ ) is higher than STHE (average $\mathrm{Q}=6106.05$ $\mathrm{kW}$ ) because the average UO of PHE is higher than STHE.

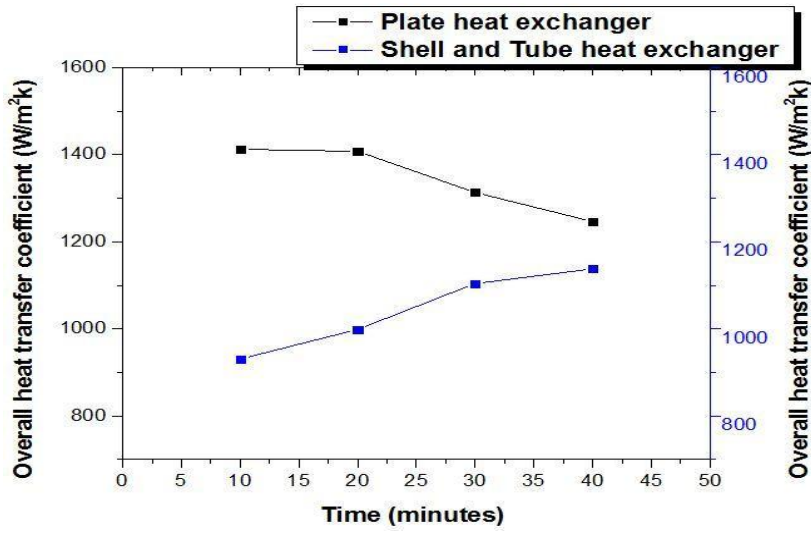

Figure7. Comparison of $U_{0}$ of PHE and STHESTHE and PHE

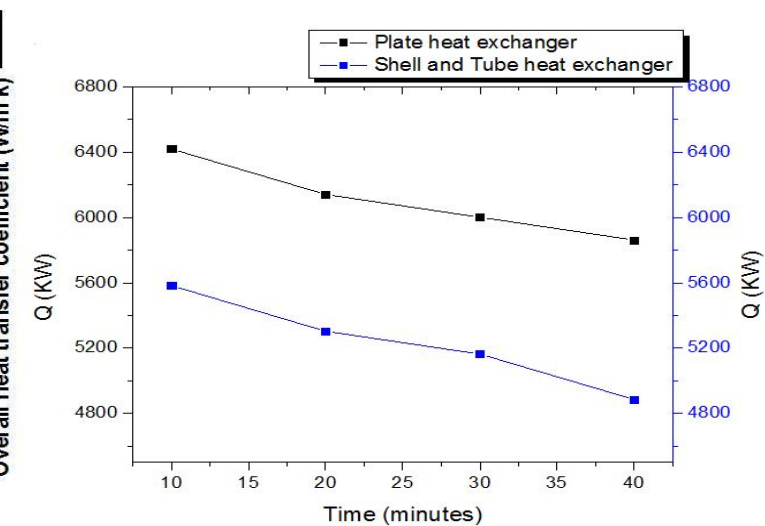

Figure8. Comparison of $Q$ in

\section{Conclusions}

The experimental and theoretical comparison study on shell and tube heat exchanger and plate type heat exchanger has been performed for a heat load of $6000 \mathrm{kcal} / \mathrm{hr}$. Following conclusions are drawn.

- Experimental results show that the average OHTC of Plate heat exchanger is $30.96 \%$ more than Shell and Tube heat exchanger because the geometry of plates, decrease in conductive and convective resistance in the plate heat exchanger.

- Heat transfer rate is directly dependent on OHTC and LMTD. 
- The plate heat exchanger has $9.67 \%$ less heat transfer area than Shell and Tube heat exchanger. Hence Plate heat exchanger is compact.

- COP of Plate heat exchanger is more than COP of Shell and Tube heat exchanger by $4.42 \%$.

\section{REFERENCES}

[1] Dawit Bogale, "Design and Development of Shell and Tube Heat Exchanger for Harar Brewery Company Pasteurizer Application (Mechanical and Thermal Design)", AJER/VOL.3/Issue 10/ 2014/99-109.

[2] Tisekar Salman W, MukadamShakeeb A, Vedpathak Harshad S, Rasal Priyanka K, Khandekar S. $B$, "Performance analysis of corrugated plate heat exchanger with water as working fluid", in International Journal of Research in Engineering Technology (IJRET), 2016.

[3] Avinash D. Jadhav, Tushar A. Koli, Vijay H. Patil, "A critical review on different heat exchangers used for heat transfer between two fluids", in International Journal of Engineering, Business and Enterprise Applications (IJEBEA), 2014.

[4] Sandeep K. Patel, Alkesh M. Mavani, "Heat Exchanger Thermal Design with Optimization of Mass Flow Rate Baffle Spacing", IJAERS/VOL.II/Issue I/Oct.-Dec.,2012/130-135.

[5] Vindhya Vasiny Prasad Dubey, Raj Rajat Verma, Piyush Shanker Verma, A.K. Srivastava, "Shell \& Tube Type Heat Exchangers: An Overview".in International journal of research in Aeronautical and Mechanical engineering, Vol.2 Issue.6, June 2014, Pgs: 1-7.

[6] Frashid Bagheri, M. Fakoor-Pakdaman, Majid Bahrami,"Utilization of orthographic graphite plate in plate heat exchangers analytical modelling", in International journal heat and mass transfer 77(2014),301-310.

[7] Yasuyuki Ikegami, Sami Mutair, Yusuke Kawabata,"Experimental and Numerical Investigations on Plate-Type Heat Exchanger Performance", Scientific research publishing, 23 March 2015.

[8] Sreejith K., Basil Varghese, Deepak Das, Delvin Devassy, Harikrishnan K., Sharath G. K, "Design and Cost Optimization of Plate Heat Exchanger", Research Inventy: in International Journal of Engineering and Science Vol.4, Issue 10 (October2014), PP 43-48.

[9] S. Muthuraman, "Investigation of Brazed Plate Heat Exchangers with Variable Chevron Angles", in American Journal of Engineering Research (AJER), 2013.

[10] Process Heat Transfer by D.Q. Kern - 21st edition,1983.154-169.

[11] Heat Exchangers- selection, rating and thermal design by SadiKakac-second edition - 413-461.

[12] Heat transfer equipment by R.K. Shah-page 634-78. 